\title{
Effects of HACCP System Implementation on Medicine Use and Productivity of Swine Farms in Korea
}

\author{
Jea-Jin Cho ${ }^{1}$, Seung Hee Baek ${ }^{1}$, Dong-Gyun Lim¹, Su II Pyo ${ }^{1,2}$, Won Cheol Lee ${ }^{1,2}$, and In Sik Nam,2* \\ ${ }^{1}$ Korea Livestock Products HACCP Accreditation Service, Anyang 430-731, Korea \\ ${ }^{2}$ Collage of Agriculture and life Sciences, Hankyong National University, Ansung 456-749, Korea
}

\begin{abstract}
This study was conducted to examine the effect of HACCP implementation on the cost of medicine use, antibiotic utilization, and productivity of swine in Korea. Data were collected from forty-five swine farms before and after implementation of a HACCP system. The cost of medicine used, the number of different antibiotics used and the number of feeds containing antibiotic supplements added at the feed company tended to be lower $(p>0.05)$ after HACCP implementation. Additionally, the number of feeds containing antibiotics supplemented at the farm was significantly lower after HACCP implementation $(p<0.05)$. Moreover, the number of piglets born per sow per year and pigs marketed per sow per year were higher after HACCP implementation $(22.0,20.0)$ than before HACCP implementation $(20.4,18.9)$. These results suggest that implementation of HACCP systems on swine farms may provide beneficial effects such as reduction of medical expenses and improved productivity, as well as increased safety of livestock products for consumers.
\end{abstract}

Key words: HACCP system, swine, productivity, antibiotics

\section{Introduction}

Many Asian countries including Korea are currently utilizing more intensive livestock operation systems compared to western countries, especially in the swine industry, to improve their productivity within a limited area of land (Kim et al., 2005). However, intensive livestock systems have created problems such as reduced immune function and poor disease control of pigs (Song et al., 2006). For these reasons, producers have started to supplement diets of swine with high amounts of antibiotics.

Antibiotics have been used as therapeutic agents, as growth promoters and for increasing the efficiency of feed usage (Chinabut and Puttinaowarat, 2005). Antibiotic supplementation in swine diets improved the rate of growth from $4.2 \%$ to $16.4 \%$ and feed efficiency from $2.2 \%$ to $6.9 \%$ as well as controlling disease (Hays, 1991). For this reason, antibiotics have been constantly used in pig production since their first introduction into feeding programs in 1950 (Hays, 1991). There can be no doubt that antibiotics continue to provide substantial economic

\footnotetext{
*Corresponding author : In Sik Nam, Korea Livestock Products HACCP Accreditation Service, Gyeonggi Venture Anyang Technical College Center, Anyang 430-731, Korea. Tel: 82-31390-5266, Fax: 82-31-465-6699, E-mail: insiknam@hotmail. com
}

benefits to pig producers. In recent years, however, antibiotic supplementation in animal feeds has resulted in bacteria developing resistance to the antibiotics. Furthermore, antibiotic residues which are hazardous to human health have been found in animal products (Rhodes et al., 2000; Suh and Song, 2006).

In Korea, the safety of livestock products has become a major issue of concern. In several countries, including Korea, hazard analysis critical control point (HACCP) systems have been introduced with regard to product hygiene and safety (Codex Alimentarius Commission, 2001). This has meant that the livestock market has moved towards demanding higher safety food products "from farm to table".

The HACCP system was implemented on swine farms in 2006, cattle farms (dairy and beef) in 2007 and poultry farms (broilers and laying hens) in 2008 (Ministry of Food, Agriculture, Forestry and Fisheries, 2006, 2007a, 2007b, 2008a, 2008b).

HACCP was originally developed in the 1960 s to ensure safe food for astronauts and to provide a specific and systematic approach to food quality control by allowing identification of hazards and the points at which they can be controlled (Codex Alimentarius Commission, 2001). Therefore, by implementing the HACCP system, prevention or exclusion of antibiotic residues in animal 
products is possible. Additionally, this may lead to reduced usage of antibiotics in feeds.

The aim of this study was to examine the effects of implementing a HACCP system on antibiotics utilization and productivity on swine in Korea.

\section{Materials and Methods}

\section{Swine farms and data collection}

Changes in the rate of medicine utilization and number of antibiotics were examined in swine farms following implementation of HACCP system. Data were collected by visiting 45 randomly selected swine farms. For each farm, the following data were obtained: monthly expenses for medicine (MEM/per head), number of different type of antibiotics used (NDAU), number of antibiotics in feed added at the feed company (NAFC), number of antibiotics in feed added at the at the swine farm (NASF), piglets born per sow per year (PSY) and pigs marketed per sow per year (MSY), based on diary records provided at the farms for over ten months. All items were compared before and after HACCP system implementation.

\section{Statistical analysis}

Mean values before and after HACCP implementation were compared by the t-test procedure in the SAS package (SAS, 2002).

\section{Results and Discussion}

Fig. 1 provides the change of MEM between control and treatment in swine farms. The average MEM in treatment was 7,670 won/per head and that in control was 9,280 won/per head. These suggested that non-HACCP system implemented swine farms tended to spend more money for medicine utilization than HACCP system ones. NDAU of HACCP system implemented swine farm tended to decrease compare to non-HACCP system implemented farm (Fig. 2). Without significant, NAFC was changed when comparing between control and treatment in swine farms (Fig. 3). Treatment (0.51) of NAFC was tended to lower than that of control $(1.06, p>0.05)$. NASF was also compared between control and treatment (Fig. 4). NASF of treatment was significantly decreased when comparing to control $(p<0.05)$. When HACCP system was implemented in swine, PSY in treatment were increased when comparing to control (Fig. 5). Without significant, MSY also tended to increase in treatment

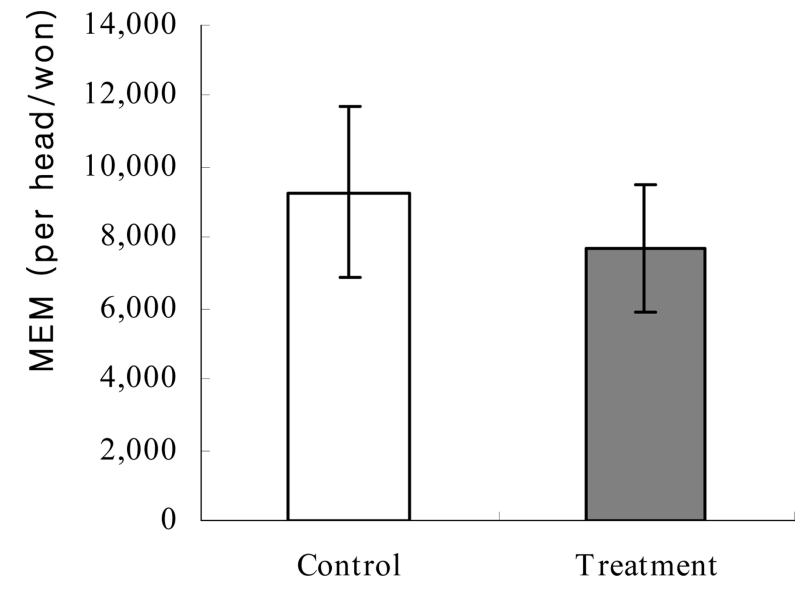

Fig. 1. Monthly expenses for medicine (MEM; Korean won per head) before (Control) and after (Treatment) HACCP system implementation on swine farms in Korea.

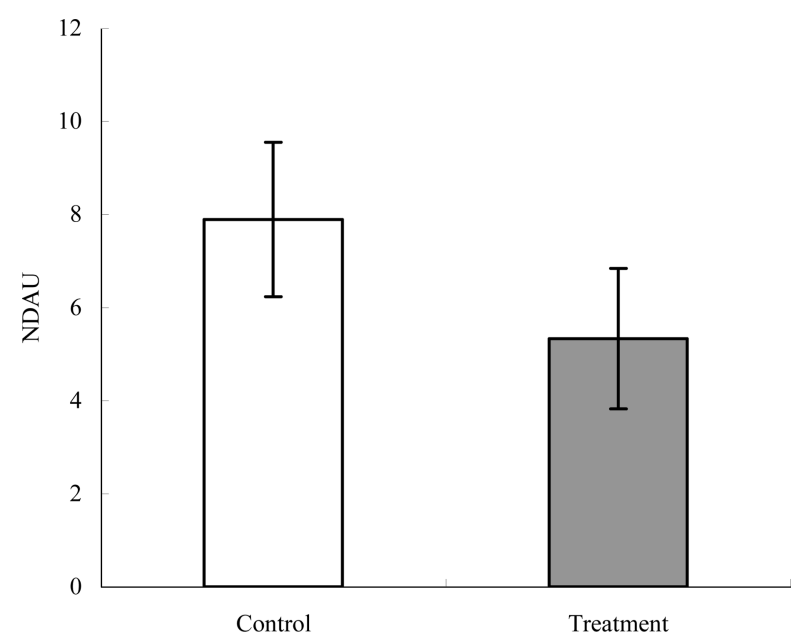

Fig. 2. Number of different type of antibiotics used (NDAU) before (Control) and after (Treatment) HACCP system implementation on swine farms in Korea.

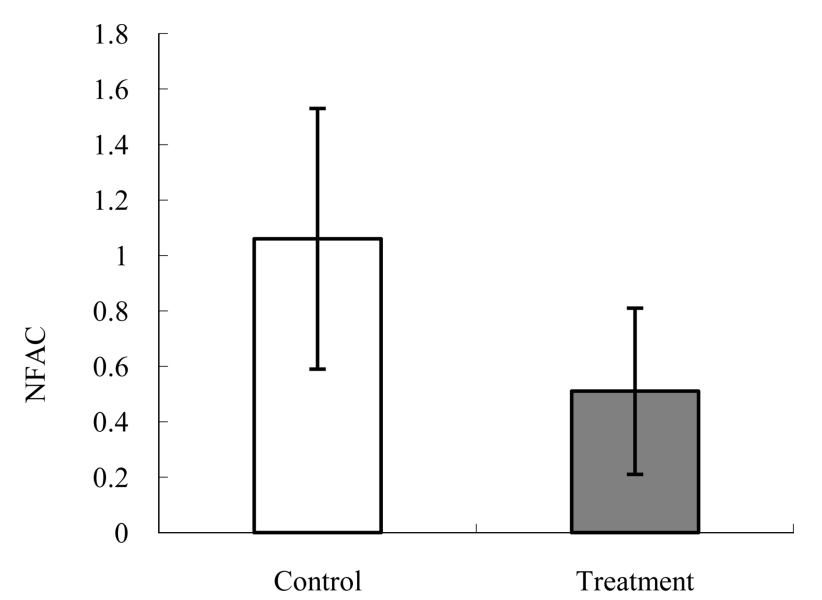

Fig. 3. Number of antibiotics in feed supplemented at the feed company (NAFC) before (Control) and after (Treatment) HACCP system implementation on swine farms in Korea. 
when comparing to control (Fig. 6). Averaged MSY in treatment was 20.03/year, which was higher than control (18.15/year).

Antibiotics have been used in the swine industry for over 50 years, mainly to increase productivity. The practice of feeding antibiotics became an integral part of nutritional strategies for all farm animals (Chikwendu et al., 2008; Chinabut and Puttinaowarat, 2005). However, there is growing concern that the wide use of antibiotics in livestock feed is giving rise to an increasing number of antibiotic-resistant pathogens in addition to presenting antibiotic residues in animal products (Chee-Sanford, 2001; Dowson et al., 1994; Hunter et al., 1992; Summers, 2002). This study showed a significant reduction of antibiotics usage after swine farms implemented HACCP

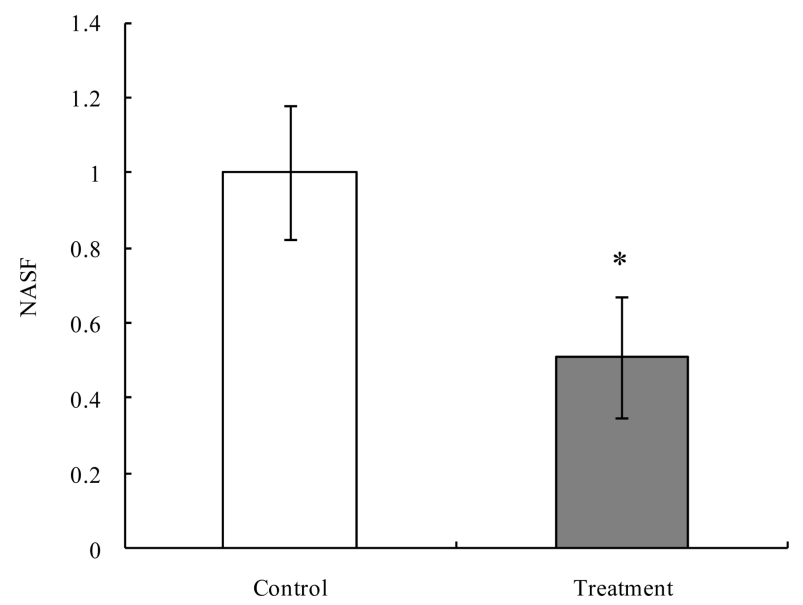

Fig. 4. Number of antibiotics in feed supplemented at the swine farm (NASF) before (Control) and after (Treatment) HACCP system implementation on swine farms in Korea.

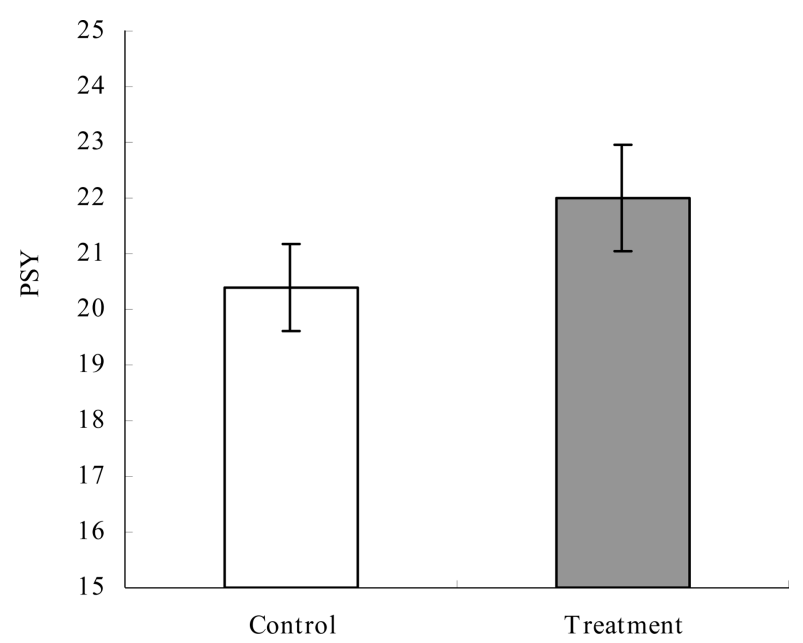

Fig. 5. Number of piglets per sow per year (PSY) before (Control) and after (Treatment) HACCP system implementation on swine farms in Korea.

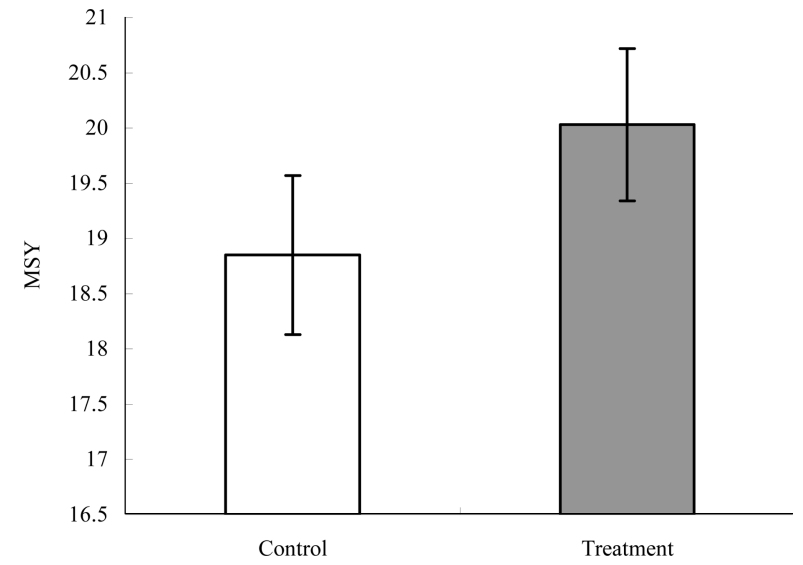

Fig. 6. Pigs marketed per sow per year (MSY) before (Control) and after (Treatment) HACCP system implementation on swine farms in Korea.

systems (Fig. 4). In Korea, the HACCP system at the farm level combines a prerequisite program and HACCP management. The prerequisite program includes bio-security management, farm facility management, farm sanitation management, feed, animal medicine and drinking water management, disease management and carry in and shipment management (Ministry of Food, Agriculture, Forestry and Fisheries, 2008c). The HACCP principle of the on-farm HACCP system in Korea totally follows the CODEX recommendation that consists of five preparation steps (assemble HACCP team, describe product, identify intended use, construct flow diagram and on-site conformation of flow diagram) and seven principles of HACCP system (conduct a hazard analysis, determine the critical control point, establish critical limits, establish a system to monitor control of the CCP, establish corrective action to be taken when monitoring indicates that a particular CCP is not under control, establish procedures for verification to confirm that the HACCP system is working effectively and establish documentation concerning all procedures and records appropriate to these principles and application) (Codex Alimentarius Commission, 2001). Therefore, the HACCP principles applied on farm and in food processing are the same.

Antibiotic administration is normally selected as a critical control point (CCP) in the HACCP system implemented on swine farms in Korea (Ministry of Food, Agriculture, Forestry and Fisheries, 2008c). When a pig is given an antibiotic by injection or through feed supplementation, the pig must not be shipped until the antibiotic residual time has elapsed according to the $\mathrm{CCP}$ of the HACCP system (Ministry of Food, Agriculture, Forestry and Fisheries, 2008c). In particular, feed, animal medi- 
cine and drinking water management section in the prerequisite program of HACCP system provides additional support for controlling and decreasing medicine use for swine. Therefore, when a HACCP system is implemented on swine farms, a reduction of medical usage such as antibiotics and the shipment of pig after the antibiotic residual time has elapsed, is expected.

HACCP implementation on a swine farm might affect PSY and MSY (Fig. 5 and Fig. 6). The average PSY and MSY in Korea is quite low compared to western countries (Song et al., 2007). Farms having a low MSY and PSY may be intensive swine operation systems which are difficult for controlling disease (Song et al., 2006) or odors (McGinn, 2001). The average MSY of a typical swine farm in Korea was 16.4 in 2002 and 13.6 in 2006 (Song et al., 2007). However, in our previous study, the average PSY and MSY of swine farms that implemented a HACCP system were 22.27 and 19.25, respectively (Nam et al., 2008), which was similar to results provided in the current study. To increase PSY and MSY, disease management and farm sanitation management might be required.

In conclusion, implementation of HACCP system on swine farms can be used to increase pork safety by reducing antibiotic utilization and keeping within the antibiotic residual time frame when pigs are to be shipped. In addition, Further study required to investigate the rate of microbial contamination, e.g. with Escherichia-coli and Salmonella spp., before and after HACCP system-implementation on swine farms.

\section{Acknowledgement}

The author would like to express sincere thanks to the forty five swine farm owners for providing their help and data to support this paper.

\section{References}

1. Chee-Sanford, J. C., Aminov, R. I., Krapac, T. J., GarrignesJean, N., and Mackie, R. I. (2001) Occurrence and diversity of tetracycline-resistance genes in lagoons and ground water underlying two swine production facilities. Appl. Environ. Microbiol. 67, 1494-1502.

2. Chikwendu, C. I., Nwabueze, R. N., and Anyanwu, B. N. (2008) Antibiotic resistance profile of Escherichia coli from clinically healthy pigs and their commercial farm environments. J. Mocrobiol. Res. 2, 12-17.

3. Chinabut, S. and Puttinaowarat, S. (2005) The choice of disease control strategies to secure international market access for aquaculture product. Pro. Fish. Vaccinol. 121, 255-261.

4. Close, W. H. (2000) Producing pigs without antibiotic growth promoters. Advan. Pork Prod. 11, 47-56.

5. Codex Alimentarius Commission. (2001) Food hygiene basic texts. Codex Alimentarius - Joint FAO/WHO food standards programs, $3^{\text {rd }}$. Bernan Association, Lanham, MD.

6. Dowson, C., Coffey, T., and Spratt, B. (1994) Origin and molecular epidemiology of penicillin-binding-protein-mediated resistance to beta-lactam antibiotics. Trends Microbiol. 2, 361-366.

7. Hays, V. W. (1991) Effects of antibiotics. In: Growth regulation in farm animals. Pearson, A. M. and Dutson, T. R. (eds) Elsevier Applied Science, London, pp. 299-320.

8. Hunter, H. J., Shelley, J. C., Walter, J. R., Hart, C. A., and Benneth, M. (1992) Apramycin resistance plasmids in Escherichia Coli: Possible transfer to S. typhimurium in clave. Epidemiol. Infect. 108, 271-278.

9. Kim, Y. Y., Kil, D. Y., Oh, H. K., and Han, I. K. (2005) Acidifier as alternative material to antibiotics in animal feed. Asian-Aust. J. Anim. Sci. 18, 1048-1060.

10. McGinn, S. M. (2001) Odiurs from intensive livestock operations. Advan. Dairy Technol. 13, 417-430.

11. Ministry of Food, Agriculture, Forestry and Fisheries (2006) Application of HACCP system on swine farm. Ministry of Food, Agriculture, Forestry and Fisheries, Seoul.

12. Ministry of Food, Agriculture, Forestry and Fisheries (2007a) Application of HACCP system on beef cattle farm. Ministry of Food, Agriculture, Forestry and Fisheries, Seoul.

13. Ministry of Food, Agriculture, Forestry and Fisheries (2007b) Application of HACCP system on lactating cattle farm. Ministry of Food, Agriculture, Forestry and Fisheries, Seoul.

14. Ministry of Food, Agriculture, Forestry and Fisheries (2008a) Application of HACCP system on chicken farm. Ministry of Food, Agriculture, Forestry and Fisheries, Seoul.

15. Ministry of Food, Agriculture, Forestry and Fisheries (2008b) Application of HACCP system on laying hen farm. Ministry of Food, Agriculture, Forestry and Fisheries, Seoul.

16. Ministry of Food, Agriculture, Forestry and Fisheries (2008c) Regulation of hazard analysis critical control point in processing of livestock product sanitation act, Korea.

17. Nam, I. S., Kwak, H. K., Pyo, S. I., Hwang, I. J., Kim, H. S., Lee, K. S., Kim, H. S., Kang, C. G., Lim, D. K., and Cho, J. J. (2008) Productivity analysis of HACCP applied pig farms. Kor. J. Vet. Publ. Heal. 32, 141-145.

18. Rhodes, G., Huys, H., and Swings, J. (2000) Distribution of oxytetracycline assistance plasmids between acromonads in hospital and aquaculture environments: Implication of Tn1721 in dissemination of the tetracycline assistance determinant. Appl. Environ. Microbial. 66, 3883-3890.

19. SAS (2002) SAS User's Guide, Version 6.02. SAS Institute Inc. NC.

20. Song, J. H., Jong, M. J., and Choi. S. H. (2007) A plan for economic benefit of livestock farm. Korea Rural Economic Institute, Annual Report, R558.

21. Song, J. H., Woo, B. J., Hour, D., and Park, S. I. (2006) Economic analysis of animal disease. Korea Rural Economic 
Institute, Annual Report, R519.

22. Suh, D. K. and Song, J. C. (2006) Analysis of Salmonella enterica serotype Enteritidis isolated from human and chickens by repetitive sequence-PCR fingerprinting by antibiotic resistance and plasmid profiles. J. Vet. Sci. 7, 37-41
23. Summers, A. O. (2002) Generally overlooked fundamentals of bacterial genetics and ecology. Clin. Infect. Dis. 34, 85-92.

(Received 2009.12.18/Revised 2010.5.6/Accepted 2010.5.6) 